\title{
Article \\ Effect of V Addition on Microstructure and Mechanical Properties in C-Mn-Si Steels after Quenching and Partitioning Processes
}

\author{
Gong-Ting Zhang ${ }^{1,2, *} \mathbb{C}$, Na-Qiong Zhu ${ }^{3}{ }^{\circledR}$, Bo-Wei Sun ${ }^{4}$, Zheng-Zhi Zhao ${ }^{1}{ }^{\mathbb{D}}$, Zhi-Wang Zheng ${ }^{2}$, Di Tang ${ }^{1}$ and \\ $\operatorname{Lin~} \mathrm{Li}^{4}$ \\ 1 Collaborative Innovation Center of Steel Technology, University of Science and Technology Beijing, \\ Beijing 100083, China; zhaozhzhi@ustb.edu.cn (Z.-Z.Z.); tangdi@nercar.ustb.edu.cn (D.T.) \\ 2 State Key Laboratory of Vanadium and Titanium Resources Comprehensive Utilization, Pangang Group \\ Research Institute Co., Ltd., Panzhihua 617000, China; zhiwangzheng@126.com \\ 3 College of International Vocational Education, Shanghai Polytechnic University, Shanghai 201209, China; \\ nqzhu@sspu.edu.cn \\ 4 School of Material Science and Engineering, Shanghai University, Shanghai 200444, China; \\ brucewei1@163.com (B.-W.S.); liling@shu.edu.cn (L.L.) \\ * Correspondence: gongtingzhang@163.com
}

check for

updates

Citation: Zhang, G.-T.; Zhu, N.-Q.; Sun, B.-W.; Zhao, Z.-Z.; Zheng, Z.-W.; Tang, D.; Li, L. Effect of V Addition on Microstructure and Mechanical Properties in C-Mn-Si Steels after Quenching and Partitioning Processes. Metals 2021, 11, 1306. https://doi.org/10.3390/ met11081306

Academic Editors: Frank Czerwinski and Koh-ichi Sugimoto

Received: 19 July 2021

Accepted: 13 August 2021

Published: 18 August 2021

Publisher's Note: MDPI stays neutral with regard to jurisdictional claims in published maps and institutional affiliations.

Copyright: (c) 2021 by the authors. Licensee MDPI, Basel, Switzerland. This article is an open access article distributed under the terms and conditions of the Creative Commons Attribution (CC BY) license (https:/ / creativecommons.org/licenses/by/ $4.0 /)$.

\begin{abstract}
Three C-Si-Mn Q\&P steels with different V addition after one-step and two-step quenching and partitioning $(\mathrm{Q} \& \mathrm{P})$ processes were investigated by means of optical microstructure observation, X-ray diffraction (XRD) measurement, transmission electron microscopy (TEM) characterization and particle size distribution (PSD) analysis. The effect of $\mathrm{V}$ addition on strength and ductility of the steels was elucidated by comparative analysis on the microstructure and mechanical properties as functions of partitioning time and temperature. For one-step Q\&P treatment, the mechanical properties were mainly controlled by the tempering behavior of martensite during partitioning. $\mathrm{V}$ addition was helpful to mitigate the deterioration of mechanical properties by precipitation strengthening and grain refinement strengthening. For two-step Q\&P treatment, the satisfying plasticity was attributed to the transformation-induced plasticity (TRIP) effect of retained austenite maintaining the high work hardening rate at high strain regime. The higher volume fraction of retained austenite with high stability resulted from the refined microstructure and the promoted carbon partitioning for the steel with $0.16 \mathrm{wt} \% \mathrm{~V}$ addition. However, the carbon consumption due to the formation of VC carbides led to the strength reduction of tempered martensite.
\end{abstract}

Keywords: V microalloyed Q\&P steel; microstructure; mechanical properties; precipitate size distribution; work hardening rate

\section{Introduction}

Quenching and partitioning (Q\&P) steel provides excellent mechanical properties required for automotive applications [1-4]. The Q\&P heat-treatment consists of fully austenizing or intercritical annealing followed by quenching below $M_{S}$ temperature and partitioning at the same quenching temperature (one-step Q\&P process) or at a higher temperature (two-step Q\&P process) [5,6]. The strong carbide forming elements like $\mathrm{V}, \mathrm{Nb}$, and Ti have been added into the Q\&P steels to improve the mechanical properties.

In Q\&P steels [7-10], $\mathrm{V}$ addition can increase the strength and work hardening exponent by VC carbides precipitating in ferrite and martensite. Moreover, a fewer difference in the strength of ferrite with VC precipitation and tempered soften martensite can obtain a better plasticity. Besides, V-added Transformation-Induced Plasticity (TRIP) steels were reported to obtain a good combination of strength and elongation [11-13]. Vanadium in solution may improve the strength and increase the volume fraction of retained austenite [14]. The V-alloying can increase both strength and ductility of medium Mn steel simultaneously. 
The mechanical stability of austenite grains results from the competition between grain refinement and reduced $C$ content, both of which are governed by V-alloying. By refining the grain size and enhancing the austenite stability, $\mathrm{V}$ addition improves the ductility of steels [15-18].

Due to the strong grain refinement strengthening and precipitation strengthening of niobium and titanium, $\mathrm{Nb} / \mathrm{Ti}$-microalloyed steels exhibit high product of strength and elongation $[19,20]$. However, the carbon consumption due to the formation of carbides might result in lower volume fraction and carbon concentration of retained austenite [21,22]. Furthermore, care must be taken in hot rolling of $\mathrm{Nb}$-containing steels because of its effect on deformation resistance and stability of rolling forces [23]. High content of Ti might significantly decrease the mechanical stability of reverted austenite and leads to the decrease in elongation and impact toughness due to insufficient TRIP effect [24].

As mentioned above, the addition of vanadium is beneficial to improve the mechanical properties of automobile steel sheet, but the effect of V concentration on C-Si-Mn Q\&P steels has been obscure. In the present work, the microstructure and mechanical properties of three Q\&P treated steels with different $V$ content were investigated in order to elucidate the strengthening and plasticity mechanisms.

\section{Experimental Procedure}

To study the effects of $\mathrm{V}$ addition, three experimental steels were designed and heat-treated based on thermodynamic calculation using Thermo-Calc software (ThermoCalc 2020b, Thermo-Calc Software AB, Solna, Sweden) with TCFE9 database [25] and Mucg83 program (MAP_STEEL_MUCG83, Mathew Peet and H.K.D.H. Bhadeshia, Cambridge, UK) [26]. The chemical compositions and the critical temperatures $\left(A_{1}, A_{3}\right.$, and $\left.M_{s}\right)$ of the three experimental steels are presented in Table 1 . The equilibrium phase diagrams of the three steels are shown in Figure 1. The enlarged section in the lower right corner illustrates the mole fraction of VC, i.e., FCC_A1\#2. It can be observed that the precipitation of VC carbides occurs in $0.16 \mathrm{~V}$ steel above $900{ }^{\circ} \mathrm{C}$ which is the general temperature range of final hot rolling. Ingots were prepared by purity raw material and vacuum induction melting at $10^{-1} \mathrm{~Pa}$ vacuum value. Slabs with $40-\mathrm{mm}$ thickness were hot rolled after reheating to $1200{ }^{\circ} \mathrm{C}$ to produce a 4-mm thick sheet. The hot-rolled sheets were then pickled and cold rolled to a $60 \%$ reduction.

Table 1. Chemical compositions ( $\mathrm{wt} \%$ ) and critical temperatures $\left({ }^{\circ} \mathrm{C}\right)$ of the three experimental steels.

\begin{tabular}{cccccccc}
\hline Steels & $\mathbf{C}$ & Si & Mn & $\mathbf{V}$ & $\boldsymbol{A}_{\mathbf{1}}$ & $\boldsymbol{A}_{\boldsymbol{3}}$ & $\boldsymbol{M}_{\boldsymbol{S}}$ \\
\hline $0 \mathrm{~V}$ & 0.24 & 1.50 & 1.90 & 0 & 715 & 823 & 373 \\
$0.03 \mathrm{~V}$ & 0.24 & 1.47 & 1.88 & 0.03 & 716 & 826 & 373 \\
$0.16 \mathrm{~V}$ & 0.24 & 1.52 & 1.83 & 0.16 & 715 & 840 & 370 \\
\hline
\end{tabular}

The heat-treatment cycle is schematically shown in Figure 2. All the specimens were austenized at $850^{\circ} \mathrm{C}$ for $200 \mathrm{~s}$ before quenching in a salt bath. One-step and two-step Q\&P heat-treatment partitioned at $320^{\circ} \mathrm{C}$ and $400{ }^{\circ} \mathrm{C}$, respectively, were processed for $90 \mathrm{~s}$ and $200 \mathrm{~s}$ before air cooling to room temperature.

The uniaxial tensile test was conducted with the standard specimen (according to the GB/T228.1-2010 standard, gauge length: $50 \mathrm{~mm}$, width: $12.5 \mathrm{~mm}$, thickness: $1.5 \mathrm{~mm}$ ), of which the tensile direction was parallel to the rolling direction. The tests were performed by MTS C45.305E electromechanical universal testing machine (MTS Systems Corp., Eden Prairie, MN, USA) with a strain rate of about $1 \times 10^{-3} \mathrm{~S}^{-1}$ at room temperature. And an extensometer was used to measure the strain of gauge length of the samples. The experimental results were determined by the average value of three samples. The microstructure was analyzed by optical microscope $(\mathrm{OM})$ and scanning electron microscope (SEM) after etching in $4 \%$ nital. Thin foils and carbon replicas were observed by transmission electron microscope (TEM). Foil specimens were prepared by electropolishing in a twin-jet polisher using $12.5 \%$ perchloric acid in alcohol at $-30{ }^{\circ} \mathrm{C}$. To characterize the 
precipitation of carbides, carbon extraction replica approach was used. The surface of the specimen was mechanically ground and polished before etching in $4 \%$ nital. Then, carbon was evaporated onto the etched surface. Next, the surface was scored to $\sim 3 \mathrm{~mm}$ squares and etched again in 10\% nital. Finally, the extracted replicas were rinsed with distilled water and placed on the copper grid and dried. The TEM micrographs of carbon extraction replica specimens were processed using Adobe Photoshop software to manually identify the precipitates. The precipitate size distribution (PSD) was determined using Image J software (ImageJ 1.52V, Wayne Rasband, Bethesda, MD, USA).
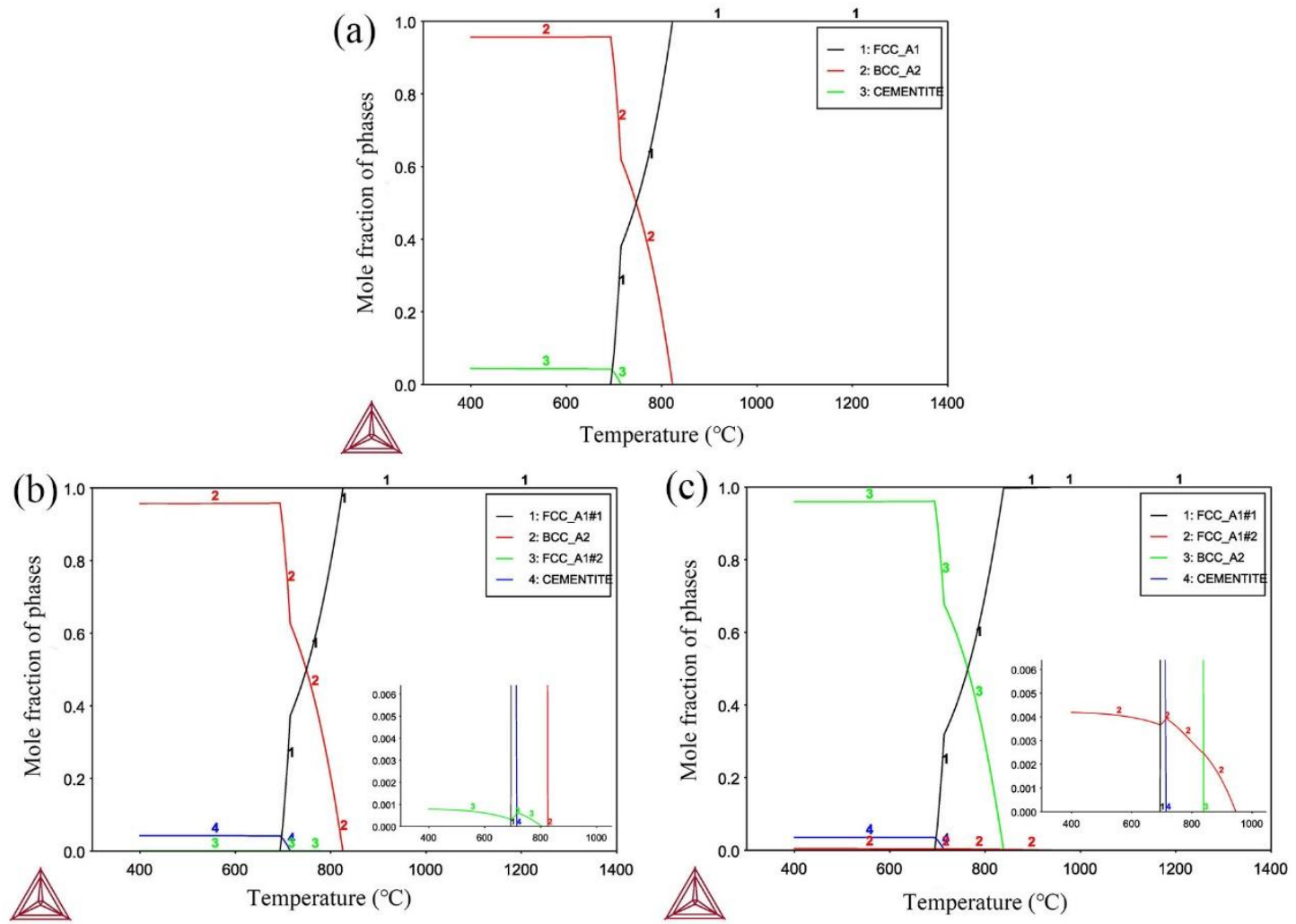

Figure 1. The equilibrium phase diagrams: (a) $0 \mathrm{~V},(\mathbf{b}) 0.03 \mathrm{~V}$ and (c) $0.16 \mathrm{~V}$.

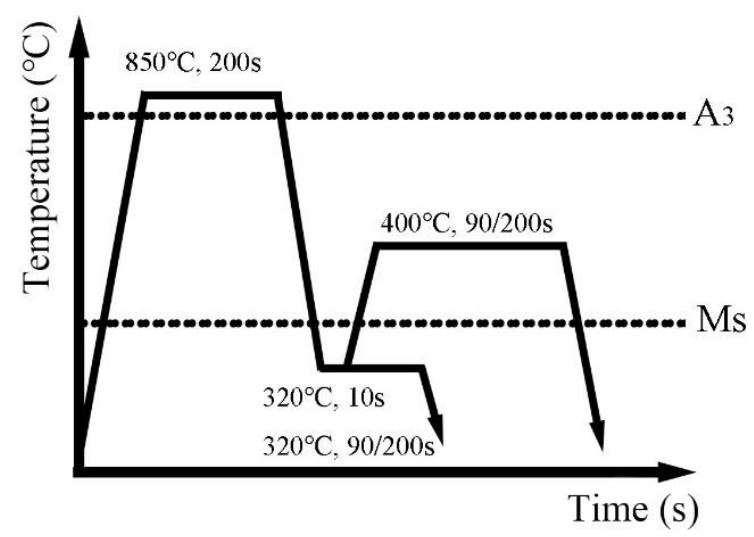

Figure 2. Heat-treatment cycle used in this study.

The volume fraction of retained austenite (RA) was measured via X-ray diffraction (XRD) with $\mathrm{CuK} \alpha$ radiation operated at $40 \mathrm{kV}$ and $200 \mathrm{~mA}$. Specimens were scanned from 
$40^{\circ}$ to $100^{\circ}$ at a scanning rate of $2^{\circ} / \mathrm{min}$. The volume fraction of RA, $V_{\gamma}$, was calculated by using the following equation:

$$
V_{\gamma}=1.4 I_{\gamma} /\left(I_{\alpha}+1.4 I_{\gamma}\right)
$$

where $I_{\gamma}$ and $I_{\alpha}$ are the integrated intensities of austenite and ferrite, respectively. In the present work, the diffraction lines of $(200)_{\alpha^{\prime}}(211)_{\alpha^{\prime}}(200)_{\gamma^{\prime}}(220)_{\gamma}$, and (311) $)_{\gamma}$ were employed to determine the value of $V_{\gamma}$ [27].

\section{Results}

\subsection{Mechanical Properties}

Table 2 lists the mechanical properties (engineering stress and strain) including ultimate tensile strength (UTS), yield strength (YS), total elongation (TE), and product of strength and elongation (PSE) of the three experimental steels subjected to the Q\&P process. Comparisons of the mechanical properties were further plotted in Figure 3. The "Sample ID" of "1ST/2ST_90/200" means "one-step/two-step" Q\&P process with the partitioning time of "90 s/200 s".

Table 2. Mechanical properties of the three experimental steels subjected to the Q\&P treatment.

\begin{tabular}{ccccc}
\hline Sample ID & UTS (MPa) & YS (MPa) & TE (\%) & PSE (GPa.\%) \\
\hline 0V-1ST_90 & $1430.8 \pm 4.4$ & $907.8 \pm 6.4$ & $10.6 \pm 0.2$ & 15.2 \\
0V-1ST_200 & $1374.8 \pm 5.4$ & $878.2 \pm 4.6$ & $9.2 \pm 0.1$ & 12.6 \\
0V-2ST_90 & $1201.0 \pm 5.4$ & $959.0 \pm 17.5$ & $13.6 \pm 1.5$ & 16.3 \\
0V-2ST_200 & $1168.7 \pm 5.5$ & $981.1 \pm 8.6$ & $12.6 \pm 1.4$ & 14.7 \\
0.03V-1ST_90 & $1419.0 \pm 1.8$ & $953.1 \pm 15.7$ & $8.2 \pm 0.0$ & 11.6 \\
0.03V-1ST_200 & $1407.8 \pm 10.7$ & $989.6 \pm 14.9$ & $7.8 \pm 0.0$ & 11.0 \\
0.03V-2ST_90 & $1141.1 \pm 12.5$ & $883.9 \pm 17.1$ & $12.8 \pm 0.1$ & 14.6 \\
0.03V-2ST_200 & $1193.2 \pm 8.4$ & $945.9 \pm 13.2$ & $12.1 \pm 1.0$ & 14.4 \\
0.16V-1ST_90 & $1405.1 \pm 9.4$ & $886.5 \pm 16.0$ & $8.6 \pm 0.4$ & 12.1 \\
0.16V-1ST_200 & $1404.6 \pm 3.3$ & $973.8 \pm 4.0$ & $8.7 \pm 0.3$ & 12.2 \\
0.16V-2ST_90 & $1175.8 \pm 4.5$ & $867.8 \pm 12.0$ & $12.8 \pm 0.3$ & 15.1 \\
0.16V-2ST_200 & $1154.7 \pm 7.1$ & $946.1 \pm 13.7$ & $14.9 \pm 1.0$ & 17.2 \\
\hline
\end{tabular}
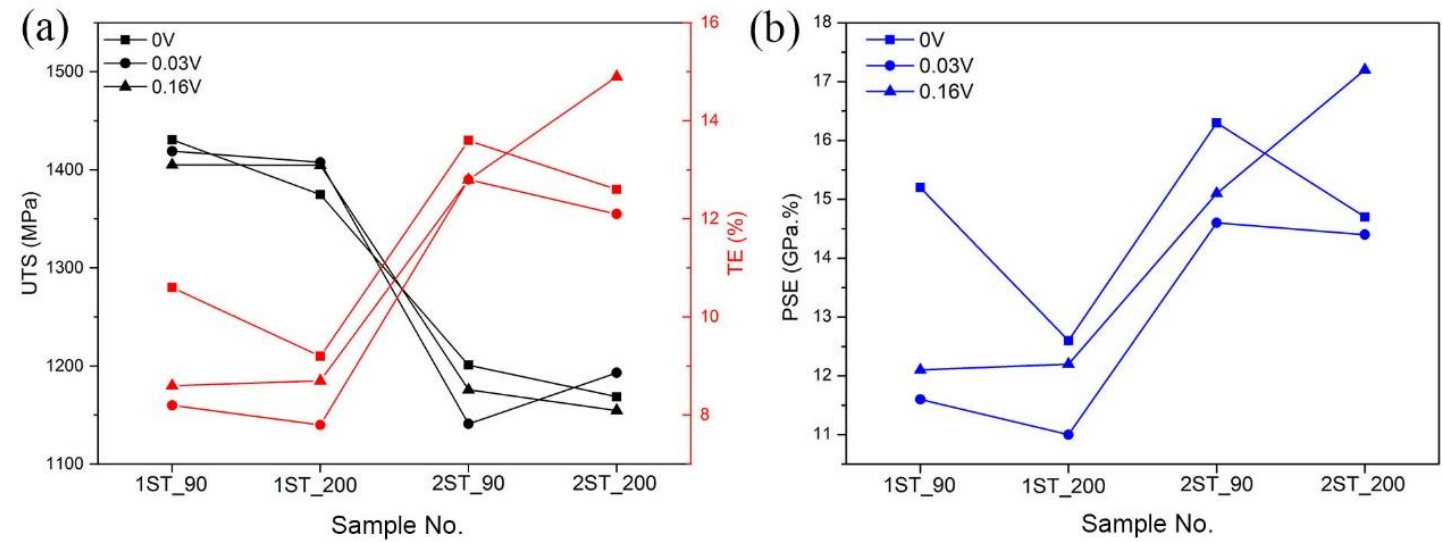

Figure 3. Mechanical properties of the three experimental steels treated by Q\&P process: (a) UTS and TE, (b) PSE.

For the one-step Q\&P-treated specimens partitioned at $320{ }^{\circ} \mathrm{C}$, the values of UTS and $\mathrm{TE}$ decrease with increasing partitioning time. A slower decreasing trend with $\mathrm{V}$ addition is observed. When partitioned for $200 \mathrm{~s}, 0.03 \mathrm{~V}$ and $0.16 \mathrm{~V}$ steels have the higher UTS values. However, the lower TE and PSE values of V microalloyed steels are shown.

Two-step Q\&P treatment partitioned at $400{ }^{\circ} \mathrm{C}$ obtains lower UTS but higher TE and PSE than one-step Q\&P treatment. The UTS, TE, and PSE values of OV steel decrease with increasing partitioning time. $0.03 \mathrm{~V}$ steel displays a slight decrease of TE and strongly 
increased UTS with an approximate PSE. Despite a small decrease of UTS, 0.16V steel obtains a greatly improved TE and PSE. After this Q\&P treatment, V microalloyed steels show the relatively lower PSE except for 0.16V-2ST_200 specimen which exhibits the highest PSE among all the Q\&P-treated specimens.

\subsection{Microstructure Observation}

Figures 4-8 show the OM and SEM micrographs of the cold-rolled and Q\&P-treated microstructure. $0.16 \mathrm{~V}$ steel characterizes a finer microstructure after Q\&P process. The refined microstructure of $0.16 \mathrm{~V}$ steel can be attributed to the pinning effect of $\mathrm{VC}$ carbides on grain boundaries during hot rolling as designed by the thermodynamic calculation presented in Figure 1.
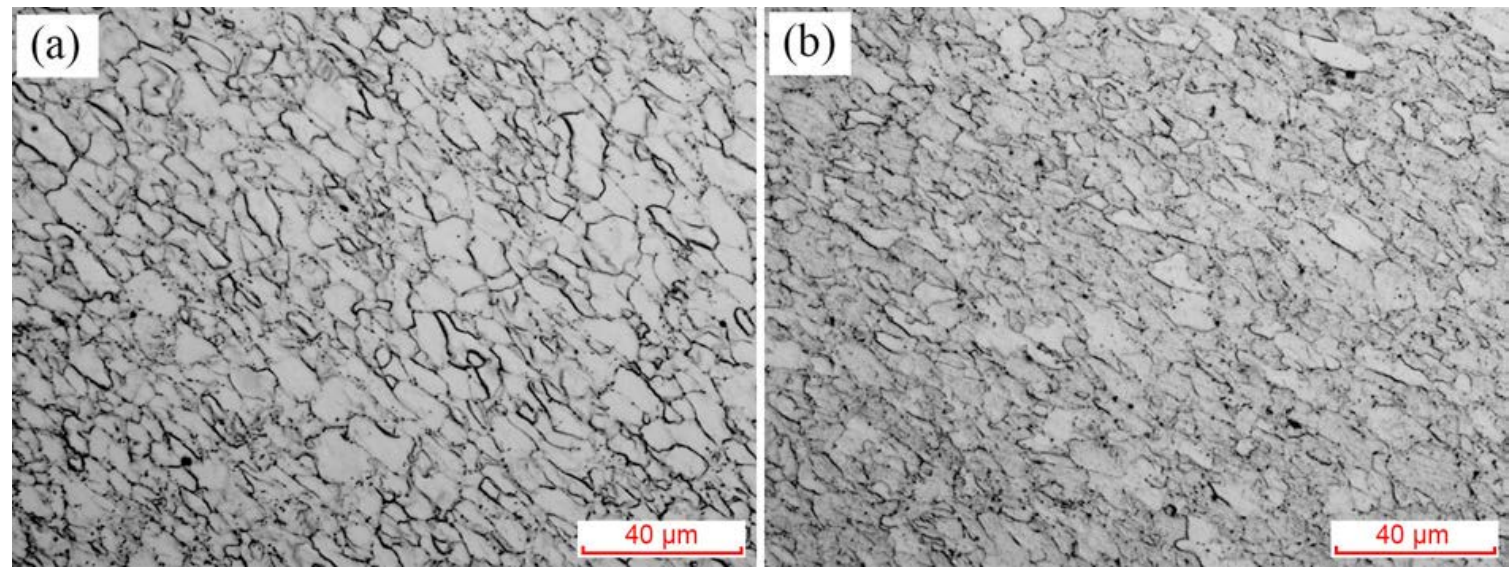

Figure 4. OM micrographs of cold-rolled microstructures: (a) $0.03 \mathrm{~V}$ and (b) $0.16 \mathrm{~V}$.
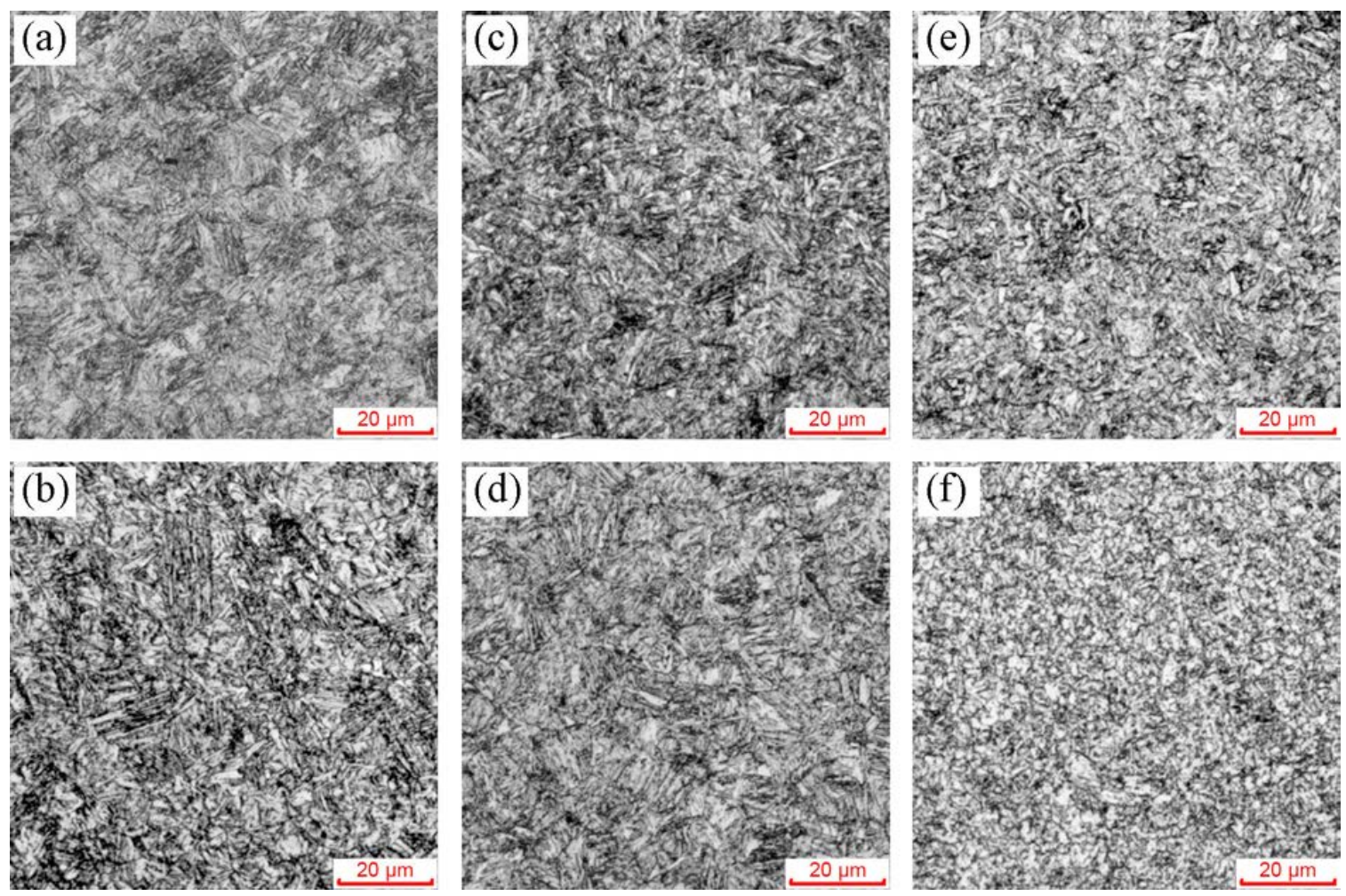

Figure 5. OM micrographs of three steels after one-step Q\&P treatment: (a,b) 0V, (c,d) $0.03 \mathrm{~V}$, and (e,f) $0.16 \mathrm{~V}$, partitioned for $(\mathbf{a}, \mathbf{c}, \mathbf{e}) 90 \mathrm{~s}$ and $(\mathbf{b}, \mathbf{d}, \mathbf{f}) 200 \mathrm{~s}$. 

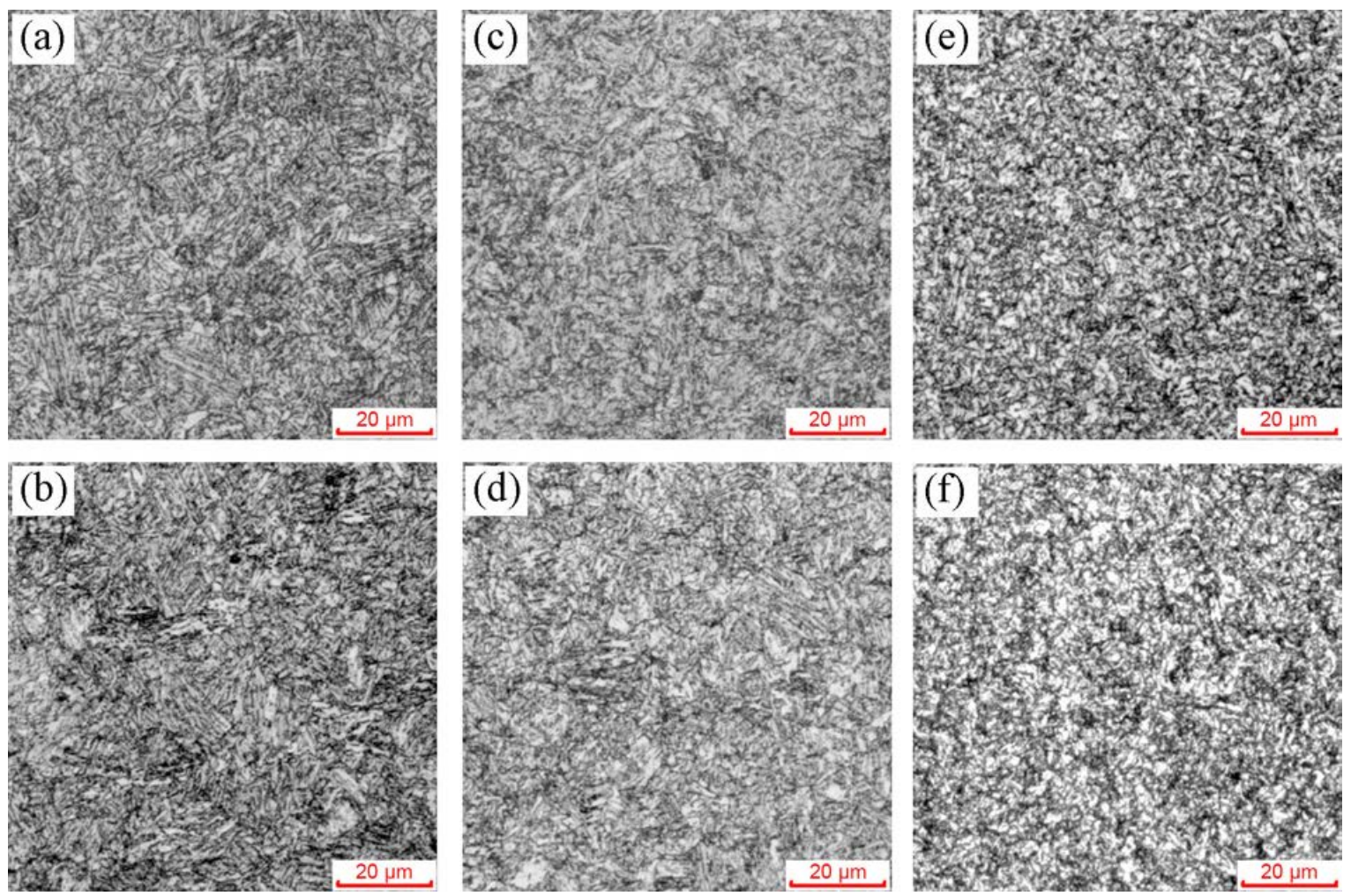

Figure 6. OM micrographs of three steels after two-step Q\&P treatment: $(\mathbf{a}, \mathbf{b}) 0 \mathrm{~V},(\mathbf{c}, \mathbf{d}) 0.03 \mathrm{~V}$, and $(\mathbf{e}, \mathbf{f}) 0.16 \mathrm{~V}$, partitioned for $(\mathbf{a}, \mathbf{c}, \mathbf{e}) 90 \mathrm{~s}$ and $(\mathbf{b}, \mathbf{d}, \mathbf{f}) 200 \mathrm{~s}$.
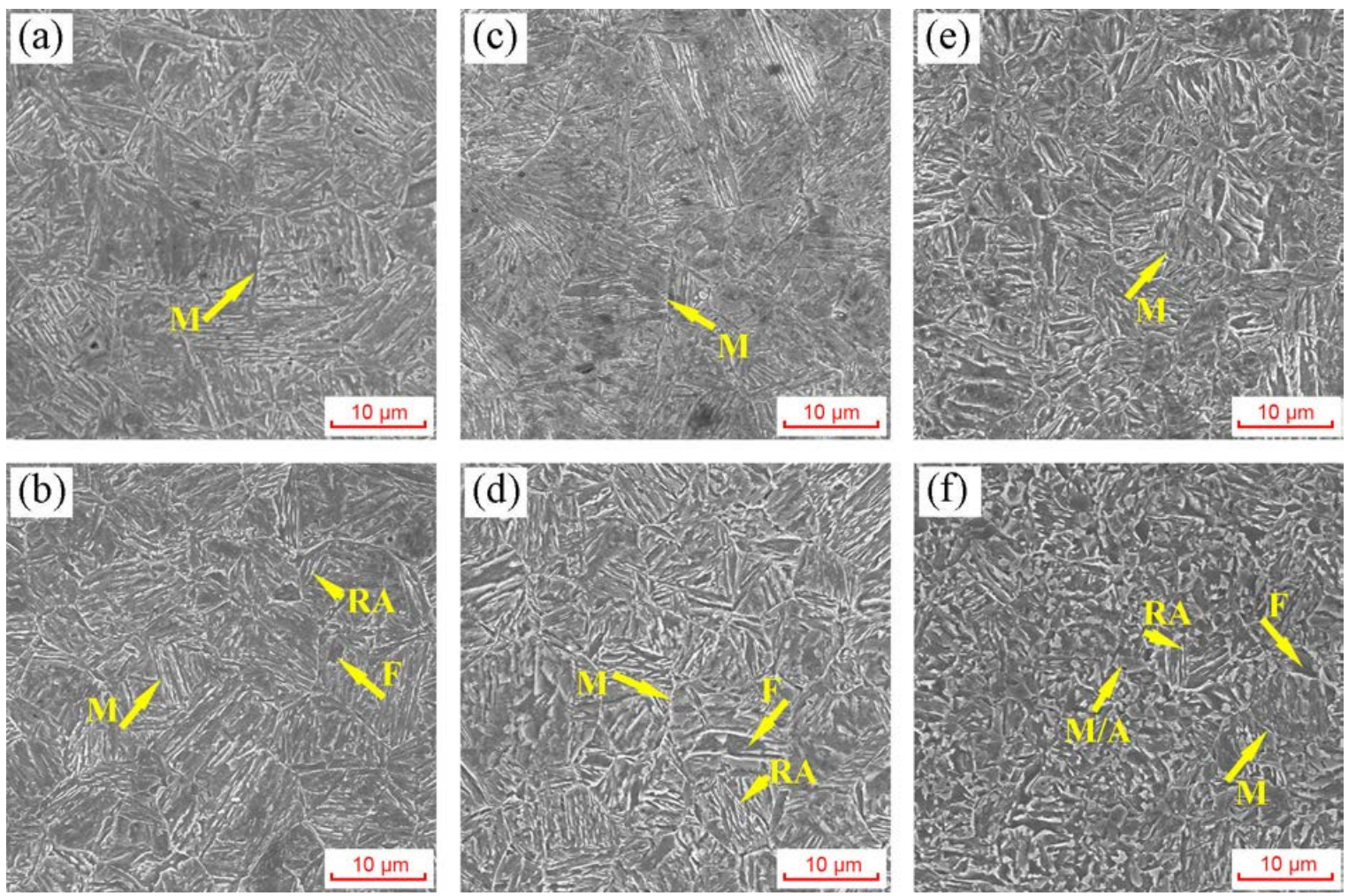

Figure 7. SEM micrographs of three steels after one-step Q\&P treatment: $(\mathbf{a}, \mathbf{b}) 0 \mathrm{~V},(\mathbf{c}, \mathbf{d}) 0.03 \mathrm{~V}$, and $(\mathbf{e}, \mathbf{f}) 0.16 \mathrm{~V}$, partitioned for (a,c,e) $90 \mathrm{~s}$ and (b,d,f) $200 \mathrm{~s}$. (M: martensite; F: ferrite; RA: retained austenite; M/A: martensite/austenite island). 

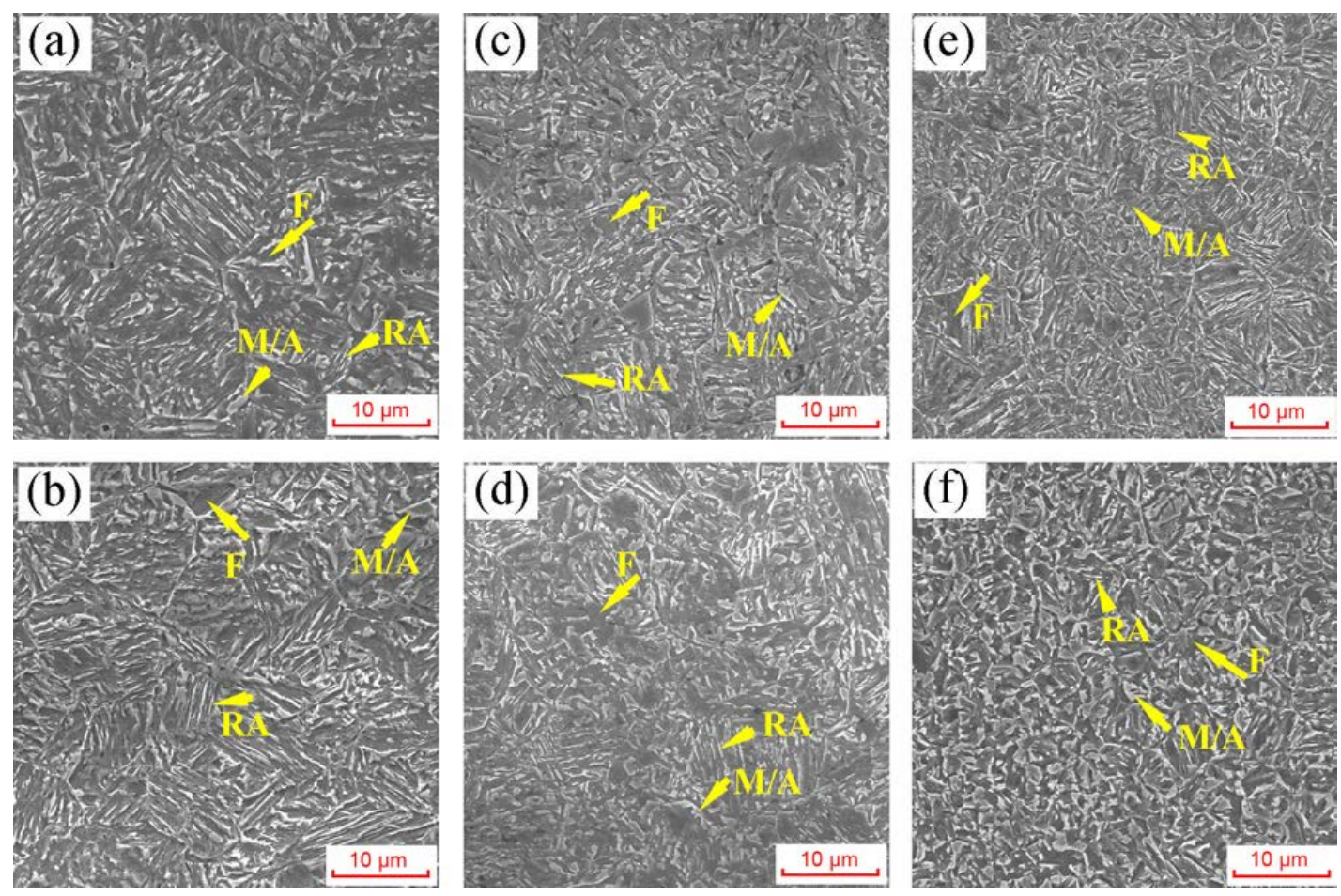

Figure 8. SEM micrographs of three steels after two-step Q\&P treatment: $(\mathbf{a}, \mathbf{b}) 0 \mathrm{~V},(\mathbf{c}, \mathbf{d}) 0.03 \mathrm{~V}$, and $(\mathbf{e}, \mathbf{f}) 0.16 \mathrm{~V}$, partitioned for $(\mathbf{a}, \mathbf{c}, \mathbf{e}) 90 \mathrm{~s}$ and (b,d,f) $200 \mathrm{~s}$. (M: martensite; F: ferrite; RA: retained austenite; M/A: martensite/austenite island).

After Q\&P process, the microstructure mainly consists of tempered martensite and RA. A block-like morphology of martensite/austenite (M/A) islands in $0.16 \mathrm{~V}$ steel can be observed which are more elongated in $0 \mathrm{~V}$ and $0.03 \mathrm{~V}$ steels. Stronger martensite tempering happens for each steel with increasing partitioning time and temperature, which also happens with increasing $\mathrm{V}$ addition during the same Q\&P heat-treatment as shown in Figures 7 and 8.

$\mathrm{XRD}, \mathrm{TEM}$, and carbon extraction replica experiments were further performed on some specific Q\&P-treated specimens to conduct a comparative investigation.

\subsection{XRD Measurement and Analysis}

The XRD patterns of Q\&P-treated specimens are presented in Figure 9. The measured volume fractions of RA are listed in Table 3. From the results in Table 3, it is concluded that the higher volume fraction of RA can be obtained after two-step Q\&P process. The higher volume fraction of RA is obtained in $0.16 \mathrm{~V}$ steel.

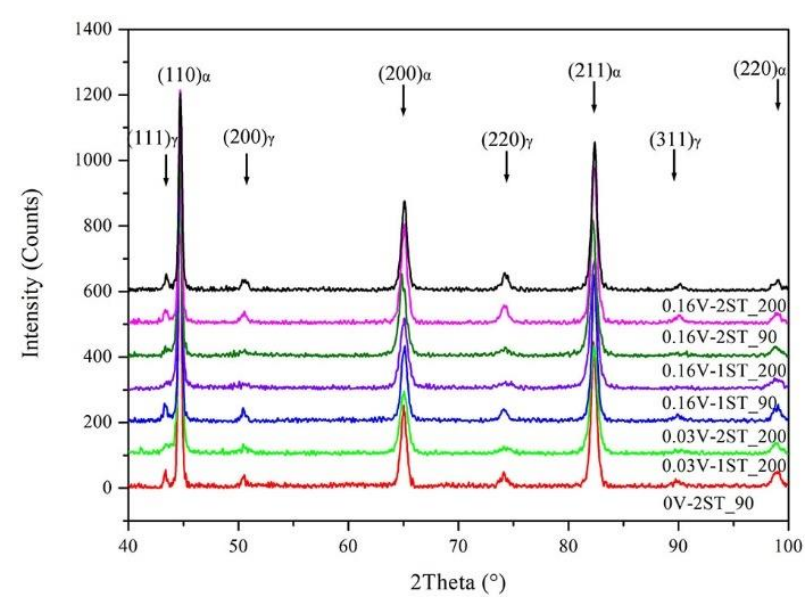

Figure 9. XRD patterns of the Q\&P-treated specimens. 
Table 3. Measured volume fractions of RA of the experimental steels after Q\&P treatment.

\begin{tabular}{cc}
\hline Sample ID & $V_{\gamma}(\mathbf{\%})$ \\
\hline 0V-2ST_90 & 8.4 \\
0.03V-1ST_200 & 5.6 \\
0.03V-2ST_200 & 8.0 \\
0.16V-1ST_90 & 3.8 \\
0.16V-1ST_200 & 4.3 \\
0.16V-2ST_90 & 10.3 \\
0.16V-2ST_200 & 9.9 \\
\hline
\end{tabular}

\subsection{TEM Characterization}

Bright-field and dark-field TEM images along with the selected area electron diffraction (SEAD) patterns as shown in Figure 10 confirm the existence of film-like RA with a face-centered cubic structure after Q\&P treatment. Figure 11 shows the typical microstructure of $0.16 \mathrm{~V}-2 \mathrm{ST}$ 200 specimen which presents the best combination of strength and ductility among all the Q\&P-treated specimens. Both carbon-depleted lath martensite (LM) and carbon-enriched twin martensite (TM) exist. The dislocation tangles as well as the dislocation networks in matrix and the interactions between dislocations and precipitates can be observed.
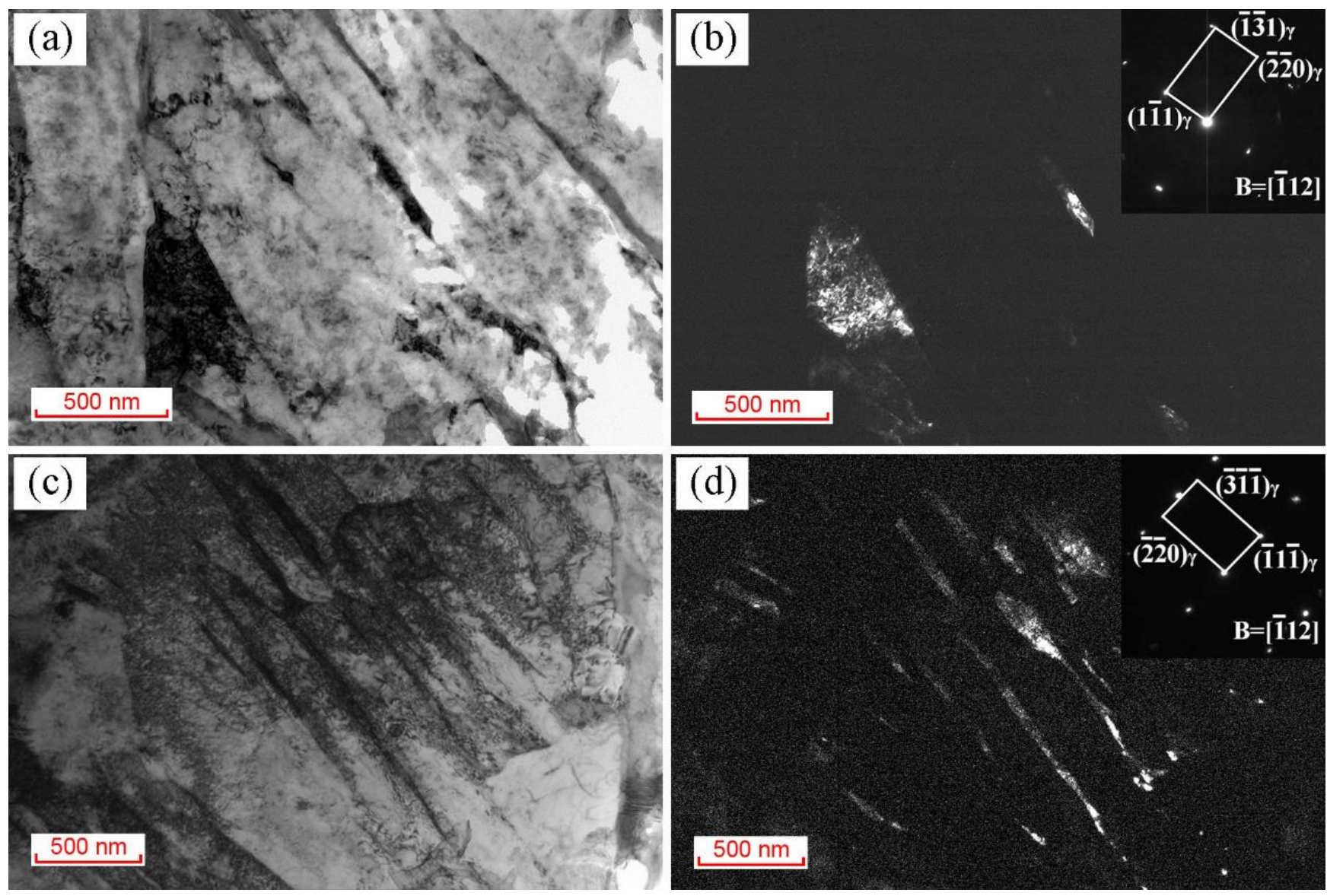

Figure 10. TEM micrographs of film-like RA after Q\&P treatment: $(\mathbf{a}, \mathbf{c})$ bright-field images and (b,d) dark-field images with SEAD patterns. 

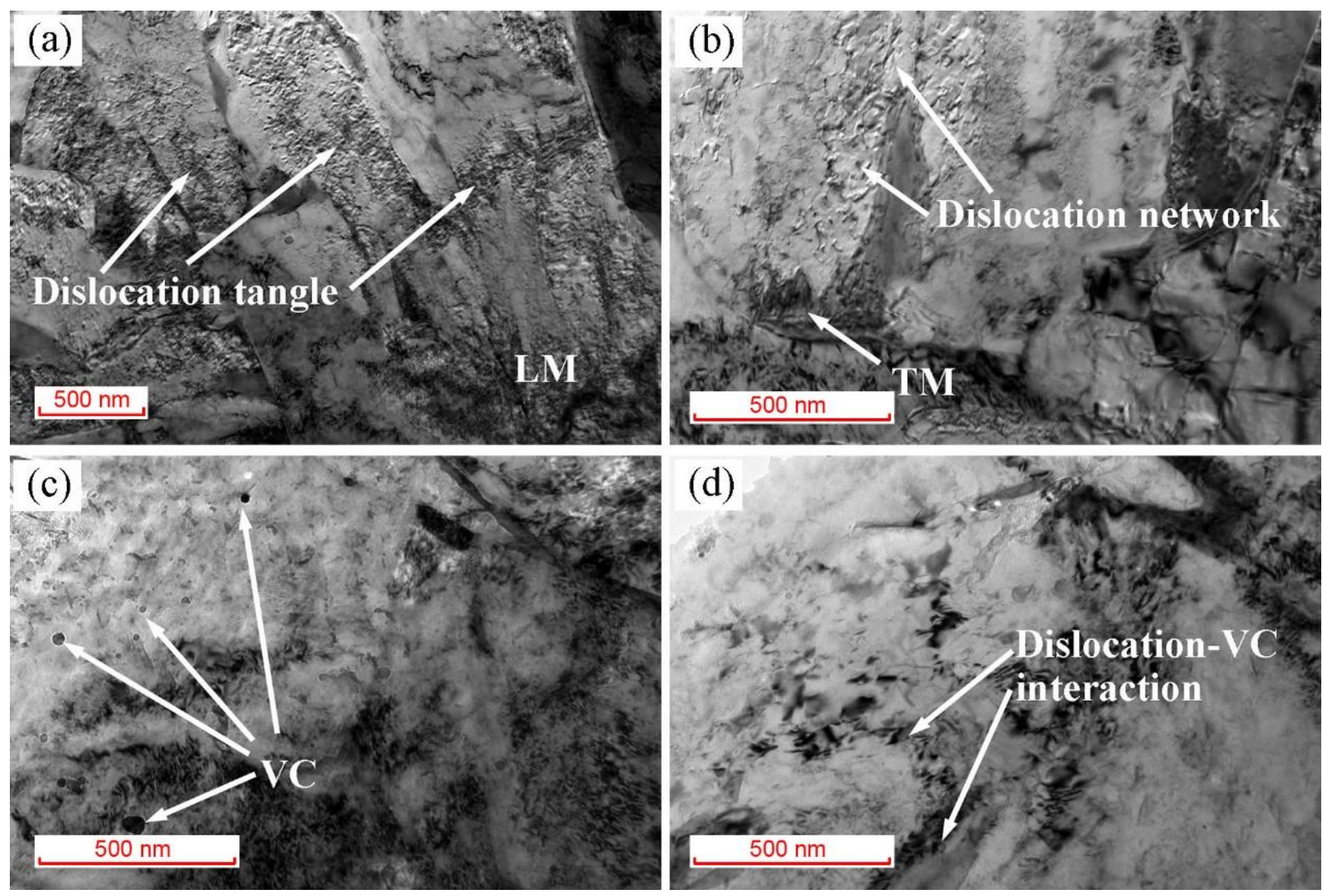

Figure 11. TEM micrographs of 0.16V-2ST_200 specimen: (a) dislocation tangle and lath martensite, (b) dislocation network and twin martensite, (c) vanadium carbide and (d) dislocation-VC interaction.

\subsection{Particle Size Distribution Analysis}

Figure 12 shows the TEM micrograph of VC precipitate with a face-centered cubic structure confirmed by SEAD pattern. To quantitatively study the precipitation behavior of VC, the PSD was analyzed based on more than $\sim 200$ VC precipitates for the specific Q\&P heat-treatment. TEM micrographs of carbon extraction replica specimens for PSD analysis are presented in Figure 13. A comparison of the determined size distribution of VC in specimens 0.03V-2ST_200, 0.16V-2ST_90 and 0.16V-2ST_200 is shown in Figure 14. Table 4 lists the corresponding information of minimum, maximum, average diameters $\left(D_{\text {min }}\right.$, $D_{\max }, D_{\text {avg }}$ ) and density of $\mathrm{VC}$ precipitates (number of $\mathrm{VC} / \mu \mathrm{m}^{2}$ ). The average diameter of VC in 0.03V-2ST_200 specimen is quite small with most of the carbides distributed within the size range of $10 \mathrm{~nm}-20 \mathrm{~nm}$. The larger size of VC in $0.16 \mathrm{~V}$ steel can be observed. Apart from the small carbides, the bigger ones $(30-40 \mathrm{~nm}$ ) also account for a certain proportion in 0.16V-2ST_90 specimen. With partitioning time from $90 \mathrm{~s}$ to $200 \mathrm{~s}$, the average diameter of carbides in $0.16 \mathrm{~V}$ steel increases with decreasing density implying the growth and coarsening of VC precipitates. 


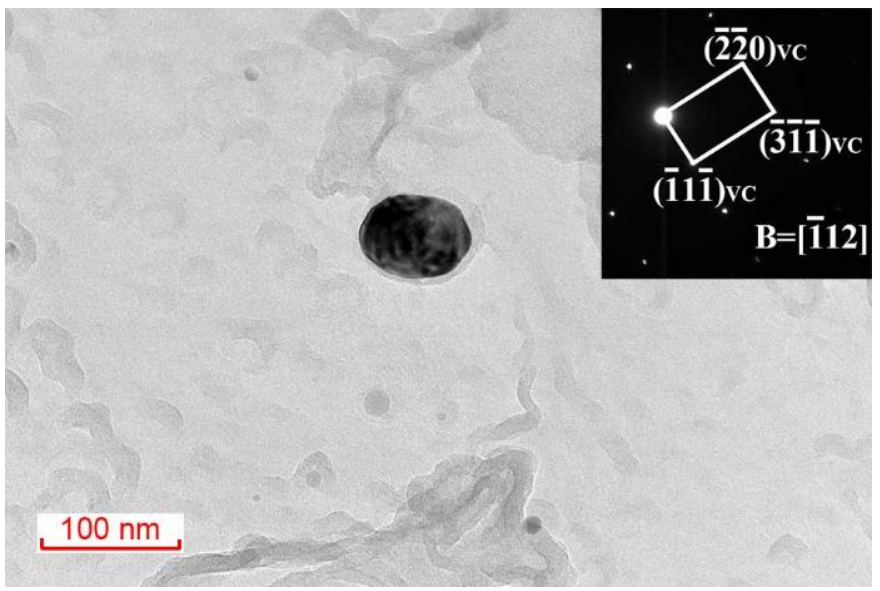

Figure 12. TEM micrograph of VC in 0.16V-2ST_200 specimen with SEAD pattern.
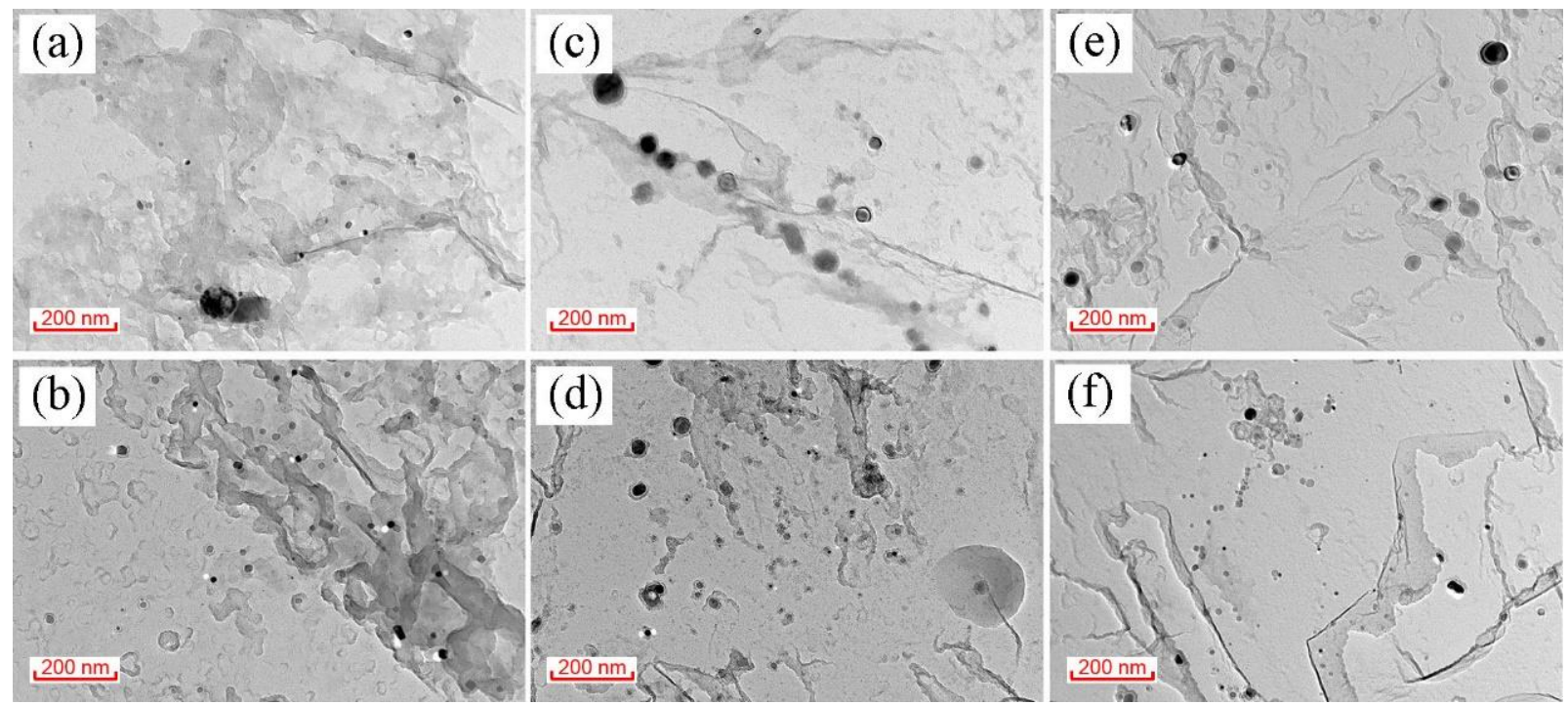

Figure 13. TEM micrographs of carbon extraction replica specimens: (a,b) 0.03V-2ST_200, (c,d) 0.16V-2ST_90, and (e,f) 0.16V-2ST_200.

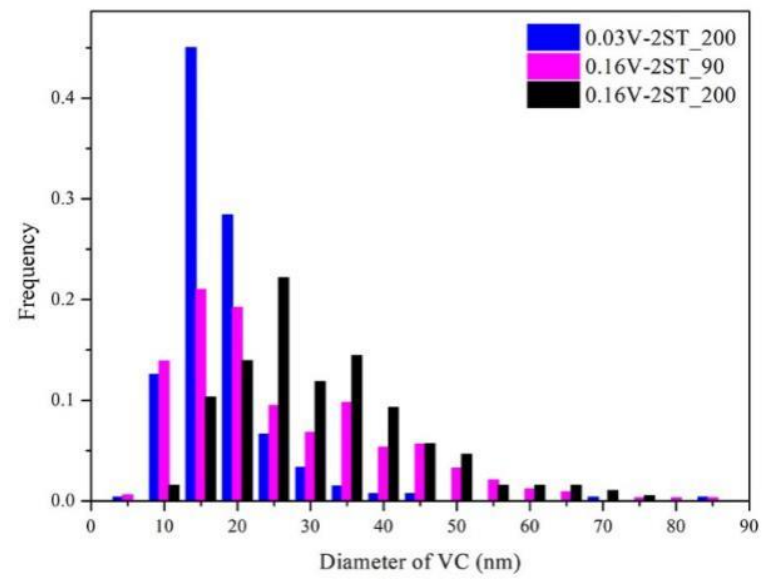

Figure 14. Comparison of the determined size distribution of VC in Q\&P-treated specimens: 0.03V2ST_200,0.16V-2ST_90 and 0.16V-2ST_200. 
Table 4. Measured $D_{\min }, D_{\max }, D_{\text {avg }}(\mathrm{nm})$, and density of $\mathrm{VC}$ precipitates (number $\left./ \mu \mathrm{m}^{2}\right)$ in Q\&P-treated steels.

\begin{tabular}{ccccc}
\hline Sample ID & $\boldsymbol{D}_{\min }$ & $\boldsymbol{D}_{\max }$ & $\boldsymbol{D}_{\boldsymbol{a v g}}$ & Density \\
\hline 0.03V-2ST_200 & 5.0 & 83.5 & 15.5 & $20 \pm 8$ \\
0.16V-2ST_90 & 3.6 & 82.3 & 23.2 & $25 \pm 9$ \\
0.16V-2ST_200 & 7.4 & 70.7 & 28.7 & $17 \pm 5$ \\
\hline
\end{tabular}

\section{Discussions}

Combined with the optical microscopy, SEM and XRD analysis, it was shown that after quenching from the austenizing temperature at $850{ }^{\circ} \mathrm{C}$, the microstructure consisted of lath martensite and untransformed austenite existed mainly in the form of film-like. The blocky austenite and island-like martensite/austenite existed as well. During the subsequent partitioning stage, two main processes were ongoing simultaneously, carbon partitioning from initial martensite to adjacent austenite and tempering behavior of initial martensite. The carbon-enriched austenite with sufficient stability was retained after quenching to the room temperature. In the present Q\&P treatment, quenching from the austenizing temperature instead of intercritical annealing temperature was applied. Thus, the higher volume fraction of filmy RA is anticipated which was confirmed by TEM observation. The tempering behavior of initial martensite during partitioning is characterized by formation of transition carbide or cementite in $0 \mathrm{~V}$ steel and vanadium carbide instead in $\mathrm{V}$ microalloyed steels. As no cementite was observed by SEM and TEM, V addition was confirmed to effectively suppress cementite formation. With increasing partitioning temperature, the stronger martensite tempering was observed. The accelerated carbon partitioning was confirmed by the increase in $V_{\gamma}$ values. Meanwhile, the growth and coarsening of VC carbides were also promoted.

In order to have a clear understanding of the relationship between microstructural evolution during Q\&P process and the mechanical properties, the work hardening behaviors of the specimens were further analyzed.

The criterion for necking [28] is shown as Equation (2). When the work hardening rate is equal to the true stress, necking should begin.

$$
\frac{d \sigma}{d \varepsilon}=\sigma \quad \text { at } \quad \varepsilon=\varepsilon_{U}
$$

where $\frac{d \sigma}{d \varepsilon}$ is the work hardening rate, $\sigma$ is the true stress and $\varepsilon$ is the true strain, $\varepsilon_{U}$ is the uniform true strain where necking begins.

The three typical comparisons of work hardening behavior changing with partitioning time were observed as illustrated in Figure 15. The work hardening rate as a function of true strain (solid line) along with the corresponding true strain-stress curve (dotted line) are presented. The work hardening rates of all the one-step Q\&P-treated specimens and two-step Q\&P-treated 0V steel decrease with increasing partitioning time as shown in Figure 15a,b. For specimen 0.03V-2ST_200, the work hardening rate is higher at low strain (plotted in the upper right corner) and lower at high strain as shown in Figure 15c. The contrary changing trend is observed for specimen 0.16V-2ST_200 as shown in Figure 15d. Comparisons of work hardening behaviors and mechanical properties of each Q\&P-treated steel with varied partitioning time come to the conclusion that a high work hardening rate at low strain regime corresponds to a high UTS while a high one maintained at high strain regime corresponds to a high TE. The present conclusion is consistent with the work of Matlock and Speer [29].

As for one-step Q\&P-treated specimens, the low volume fractions of RA were determined as listed in Table 3. As the dominating phase, the tempering behavior of initial martensite during partitioning is reasonably regarded as the controlling factor of mechanical properties. The decreased dislocation density and carbon supersaturation weaken the strength of tempered martensite [21,30]. The smaller number of dislocation-dislocation 
interactions result in the lower work hardening rate [6]. Thus, the UTS and TE decrease with increasing partitioning time. For V microalloyed steels, the precipitation of VC can increase the strength of tempered martensite $[6,9]$ which explains the higher UTS values with $200 \mathrm{~s}$ of partitioning time. Meanwhile, the refined martensitic laths have a better combination of strength and plasticity [23]. Thus, the effect of martensite tempering can be offset to some extent contributing to a slower decreasing trend of UTS and TE with increasing V content.
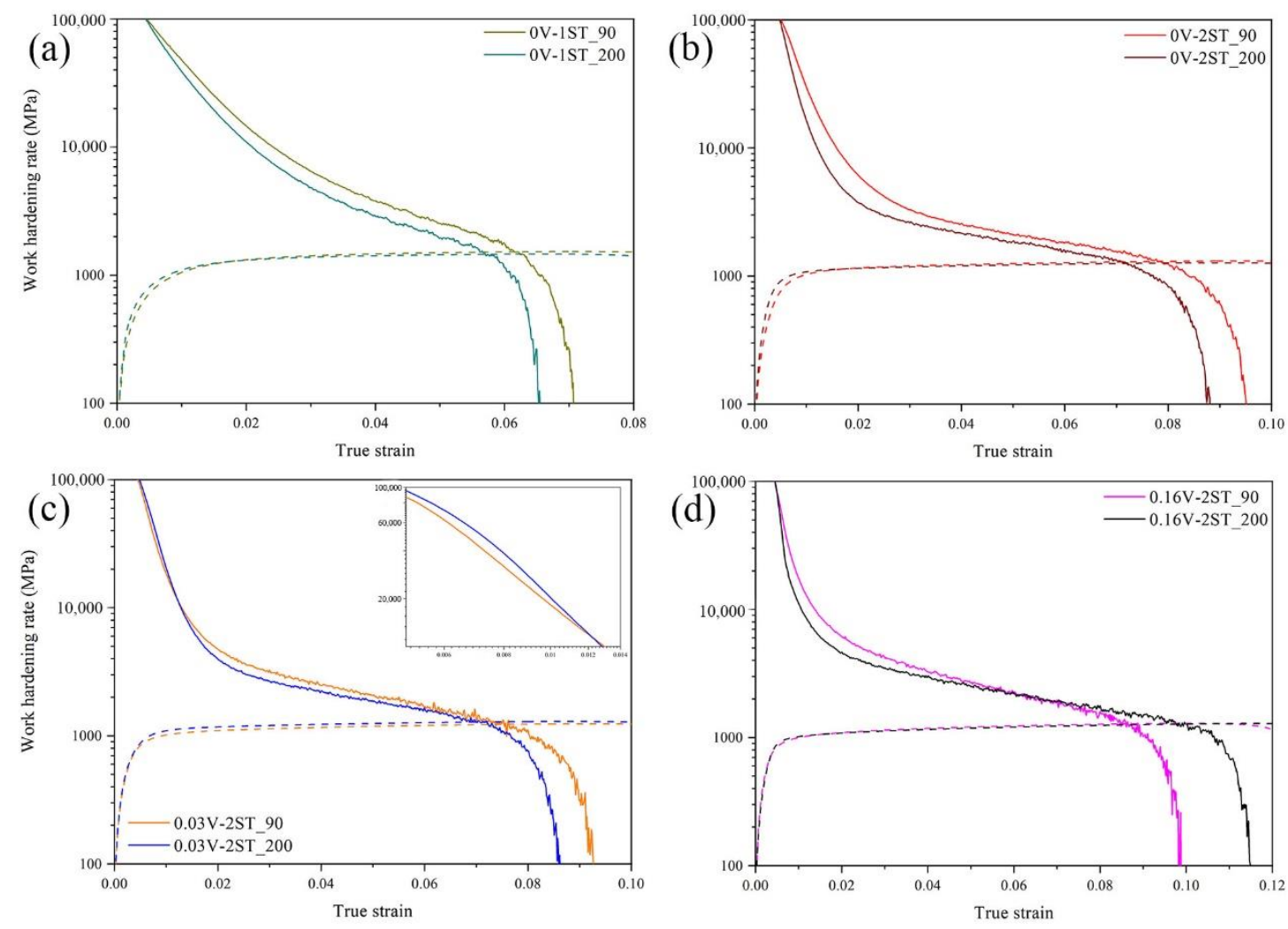

Figure 15. Work hardening rate as a function of true strain (solid line) along with the corresponding true strain-stress curve (dotted line) of specimens: (a) 0V-1ST, (b) 0V-2ST, (c) 0.03V-2ST, and (d) 0.16V-2ST.

After two-step Q\&P treatment, the higher degree of martensite tempering and carbon depletion greatly reduce the strength and increase the plasticity of tempered martensite [21]. The lower UTS and higher TE values were then obtained. Besides, the higher volume fraction of RA and the promoted growth and coarsening of VC carbides might have more pronounced effects on mechanical properties of two-step Q\&P treated specimens. As shown in Figure 15b-d, the three steels display the quite differentiated work hardening behaviors with increasing partitioning time. Further comparative analysis on the three steels after the same Q\&P treatment is shown in Figure 16. The low-strain sections were enlarged to display the work hardening behavior in the early stage of deformation and the yielding stage, respectively. The dramatic increase in work hardening rate at low strain for $0.03 \mathrm{~V}$ steel might be caused by the high density of small-sized VC carbides performing the strong precipitation strengthening effect. However, the higher work hardening rate at low strain results in reaching the instability criterion in Equation (2) at lower strain values, i.e., lower ductility [29]. 

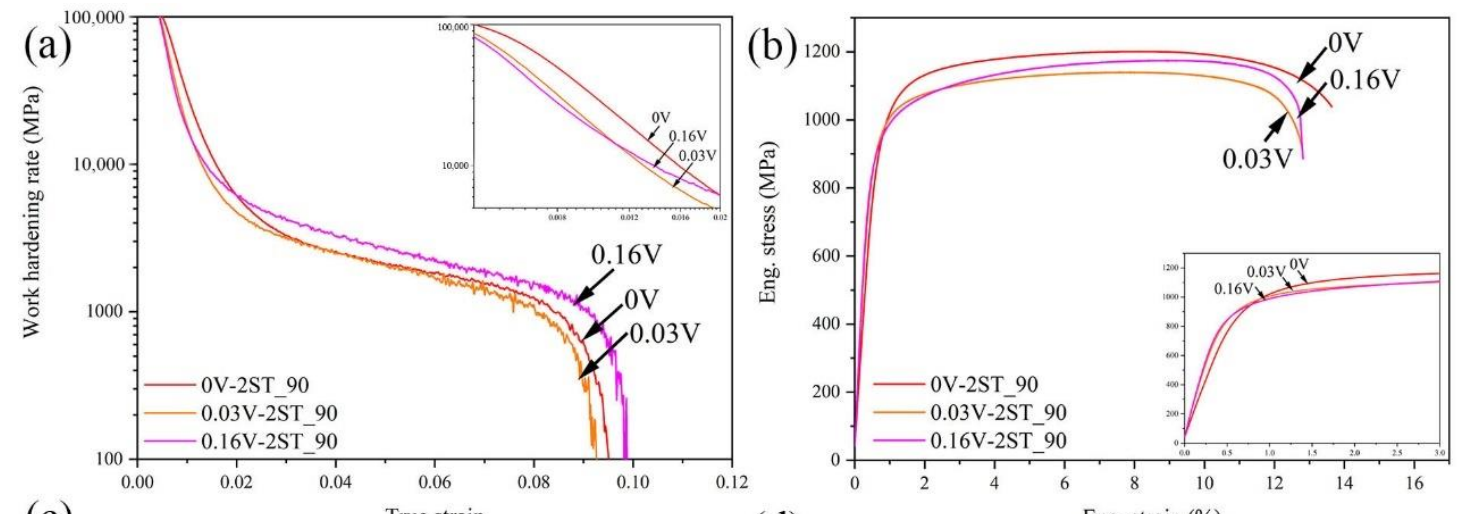

(c)
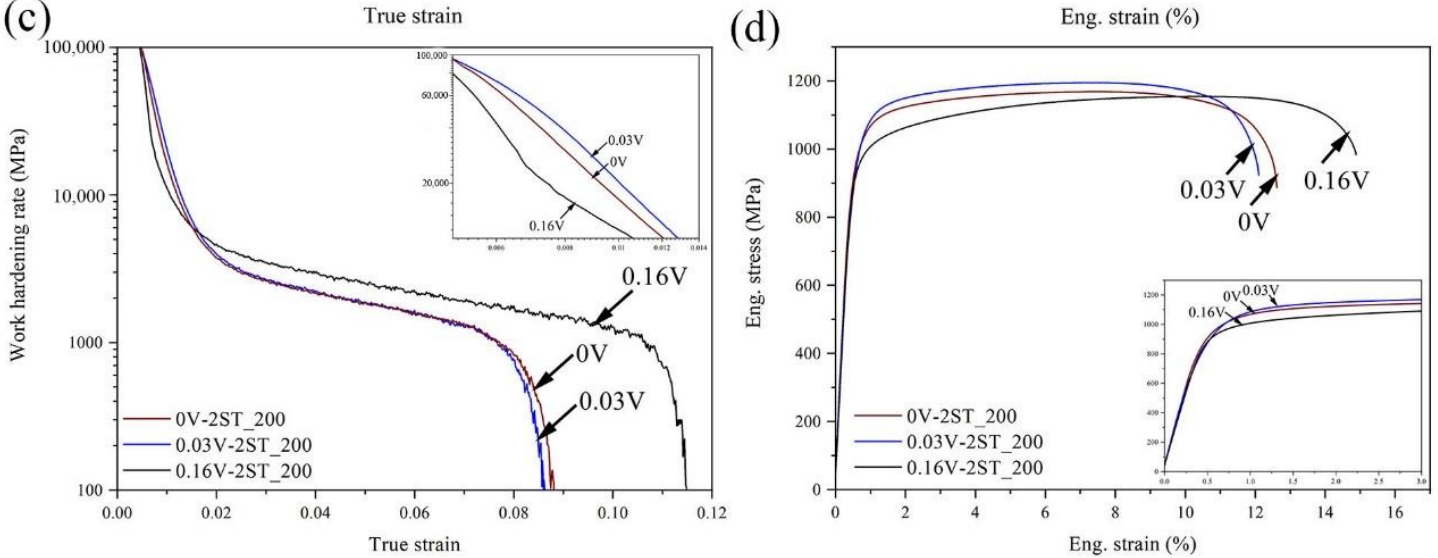

Figure 16. Comparisons of $(\mathbf{a}, \mathbf{c})$ true strain-work hardening rate and $(\mathbf{b}, \mathbf{d})$ engineering strain-stress curves of the three steels after two-step Q\&P treatment.

The precipitation strengthening can be estimated using Ashby-Orowan equation [31].

$$
\sigma_{p}=\frac{0.538 G b f^{1 / 2}}{X} \ln \left(\frac{X}{2 b}\right)
$$

where $\sigma_{p}$ is the yield strength increase (in $\mathrm{MPa}$ ), $\mathrm{G}$ is the shear modulus (in $\mathrm{MPa}$ ), $b$ is the Burgers vector (in $\mathrm{mm}$ ), $f$ is the volume fraction of particles, and $X$ is the real (spatial) diameter of the precipitates ( $\mathrm{mm}$ ).

The growth and coarsening of VC carbides in $0.16 \mathrm{~V}$ steel with prolonged partitioning time occurred. The lower volume fraction of larger-sized carbides leads to the weaker precipitation strengthening effect according to Equation (3). In addition, the carbon consumption in tempered martensite caused the reduction of strength. Thus, the low work hardening rate at low strain as well as low UTS and YS were observed and presented in Figure 16c,d for 0.16V-2ST_200 specimen. The 0.16V steel is characterized by the greatly refined Q\&P microstructure which effectively promotes the carbon diffusion from tempered martensite to austenite during partitioning [32]. Thus, the higher volume fraction of carbon-enriched austenite was retained as listed in Table 3. Figure 16a,c show that the high work hardening rate maintains at high strain regime for $0.16 \mathrm{~V}$ steel which should be attributed to the transformation from RA to martensite performing the TRIP effect. As demonstrated in Figure 16a,b with $90 \mathrm{~s}$ of partitioning time, $0.16 \mathrm{~V}$ steel presents the highest UE. However, a quick failure after necking happens resulting in the lower TE than 0V steel which might be attributed to the lower strength of tempered martensite. With prolonged partitioning time of $200 \mathrm{~s}$, the stability of RA is greatly enhanced by carbon partitioning and the refined microstructure $[7,9,33]$. The TRIP effect performed by highly stabilized RA increases the work hardening rate and maintains the high value in a large strain regime which contributes to the high strength and plasticity of $0.16 \mathrm{~V}-2 \mathrm{ST} \_200$ specimen. 


\section{Conclusions}

1. In this work, quenching from the austenizing temperature instead of intercritical annealing temperature was applied. $\mathrm{V}$ addition up to $0.16 \mathrm{wt} \%$ greatly refines the microstructure by the pinning effect of undissolved vanadium carbides during the hot rolling process. Two main processes, martensite tempering and carbon partitioning, were ongoing simultaneously during the partitioning stage. In V microalloyed steels, the precipitation, growth, and coarsening of VC carbides were observed. The Q\&P microstructures consist of tempered martensite and retained austenite, while $\mathrm{V}$ addition inhibits the cementite formation.

2. After one-step Q\&P treatment, a low volume fraction of retained austenite was obtained. The mechanical properties changing with partitioning time are mainly controlled by the tempering behavior of the dominating phase, i.e., tempered martensite. The decreasing dislocation density and carbon supersaturation in tempered martensite with increasing partitioning time result in the decrease in martensite strength and work hardening rate. The corresponding decrease of UTS, TE, and PSE values is obtained. In V microalloyed steels, the precipitation strengthening as well as grain refinement strengthening can offset the effects of martensite tempering contributing to a slower decreasing trend.

3. Compared to one-step Q\&P treatment, a high volume fraction of retained austenite and highly tempered martensite after two-step Q\&P treatment present the lower UTS, higher TE and PSE values. During partitioning at $400{ }^{\circ} \mathrm{C}$, the more sufficient carbon partitioning as well as the promoted carbide growth and coarsening leads to the quite differentiated changes in mechanical properties with partitioning time. With $\mathrm{V}$ addition of $0.03 \mathrm{wt} \%$, the precipitation strengthening effect performed by the high density of small-sized VC carbides greatly increases the UTS value. However, the higher $\mathrm{V}$ content of $0.16 \mathrm{wt} \%$ demonstrates an obvious growth and coarsening of VC carbides and the resultant carbon consumption in tempered martensite. The weakened precipitation strengthening effect and the reduction of martensite strength decrease the UTS and YS values. In addition, the refined microstructure of $0.16 \mathrm{~V}$ steel can effectively promote the carbon partitioning. The more sufficient carbonenriched small-sized retained austenite with high stability can perform the TRIP effect to maintain the high work hardening rate at high strain regime which contributes to the higher plasticity.

Author Contributions: Conceptualization, G.-T.Z.; Formal Analysis, N.-Q.Z.; Investigation, N.-Q.Z. and B.-W.S.; Methodology, Z.-Z.Z.; Resources, Z.-W.Z.; Supervision, D.T. and L.L.; Writing-Original Draft, G.-T.Z.; Writing-Review and Editing, Z.-Z.Z.; All authors have read and agreed to the published version of the manuscript.

Funding: This research received no external funding.

Data Availability Statement: Not applicable.

Conflicts of Interest: The authors declare no conflict of interest.

\section{References}

1. Speer, J.; Matlock, D.K.; De Cooman, B.C.; Schroth, J.G. Carbon partitioning into austenite after martensite transformation. Acta Mater. 2003, 51, 2611-2622. [CrossRef]

2. Maheswari, N.; Chowdhury, S.G.; Kumar, K.H.; Sankaran, S. Influence of alloying elements on the microstructure evolution and mechanical properties in quenched and partitioned steels. Mater. Sci. Eng. A 2014, 600, 12-20. [CrossRef]

3. Liu, L.; He, B.; Huang, M. The Role of Transformation-Induced Plasticity in the Development of Advanced High Strength Steels. Adv. Eng. Mater. 2018, 20, 1701083. [CrossRef]

4. YU, J.; Wang, H.; Zheng, W.; He, Y.; Wu, Y.; Li, L. Effect of the Interface Microstructure of Hot-Dip Galvanizing High-Strength Automobile Steel on Its Tensile Fracture Behaviors. Acta Metall. Sin. 2020, 56, 863-873. [CrossRef]

5. Yi, H.L.; Chen, P.; Hou, Z.; Hong, N.; Cai, H.; Xu, Y.; Wu, D.; Wang, G. A novel design: Partitioning achieved by quenching and tempering (Q-T \& P) in an aluminium-added low-density steel. Scr. Mater. 2013, 68, 370-374. [CrossRef] 
6. Findley, K.; Hidalgo-García, J.; Huizenga, R.; Santofimia, M. Controlling the work hardening of martensite to increase the strength/ductility balance in quenched and partitioned steels. Mater. Des. 2017, 117, 248-256. [CrossRef]

7. Tan, X.; Xu, Y.; Yang, X.; Wu, D. Microstructure-properties relationship in a one-step quenched and partitioned steel. Mater. Sci. Eng. A 2014, 589, 101-111. [CrossRef]

8. Tan, X.D.; Yang, X.L.; Xu, Y.B.; Hu, Z.P.; Peng, F.; Zhang, H.; Yu, Y.M.; Wu, D. Effect of Ferrite Status on Mechanical Properties of Hot-Rolled Directly Quenched and Partitioned Steel. Mater. Sci. Forum 2015, 816, 736-742. [CrossRef]

9. Peng, F.; Xu, Y.; Gu, X.; Wang, Y.; Liu, X.; Li, J. The relationships of microstructure-mechanical properties in quenching and partitioning (Q\&P) steel accompanied with microalloyed carbide precipitation. Mater. Sci. Eng. A 2018, 723, 247-258. [CrossRef]

10. Xu, Y.; Hu, Z.-P.; Zou, Y.; Tan, X.-D.; Han, D.-T.; Chen, S.-Q.; Ma, D.-G.; Misra, R. Effect of two-step intercritical annealing on microstructure and mechanical properties of hot-rolled medium manganese TRIP steel containing $\delta$-ferrite. Mater. Sci. Eng. A 2017, 688, 40-55. [CrossRef]

11. Perrard, F.; Scott, C. Vanadium Precipitation during Intercritical Annealing in Cold Rolled TRIP Steels. ISIJ Int. 2007, 47, 1168-1177. [CrossRef]

12. Zhang, G.; Zhao, Z.; Long, J.; Sheng, G.; Zheng, Z.; Tang, D. The relationship between microstructures and mechanical properties of vanadium microalloyed cold rolled ultrahigh strength steel treated by austempering. Mater. Res. Express 2019, 6, 126543. [CrossRef]

13. Krizan, D.; Spiradek-Hahn, K.; Pichler, A. Relationship between microstructure and mechanical properties in Nb-V microalloyed TRIP steel. Mater. Sci. Technol. 2014, 31, 661-668. [CrossRef]

14. Shi, W.; Li, L.; Yang, C.-X.; Fu, R.-Y.; Wang, L.; Wollants, P. Strain-induced transformation of retained austenite in low-carbon low-silicon TRIP steel containing aluminum and vanadium. Mater. Sci. Eng. A 2006, 429, 247-251. [CrossRef]

15. He, B.B.; Huang, M.X. Simultaneous Increase of Both Strength and Ductility of Medium Mn Transformation-Induced Plasticity Steel by Vanadium Alloying. Met. Mater. Trans. A 2018, 49, 1433-1438. [CrossRef]

16. Bai, S.; Xiao, W.; Niu, W.; Li, D.; Liang, W. Microstructure and Mechanical Properties of a Medium-Mn Steel with 1.3 GPa-Strength and 40\%-Ductility. Materials 2021, 14, 2233. [CrossRef] [PubMed]

17. Park, T.M.; Jeong, M.S.; Jung, C.; Choi, W.S.; Choi, P.-P.; Han, J. Improved strength of a medium-Mn steel by V addition without sacrificing ductility. Mater. Sci. Eng. A 2021, 802, 140681. [CrossRef]

18. Pushkareva, I.; Shalchi-Amirkhiz, B.; Allain, S.Y.P.; Geandier, G.; Fazeli, F.; Sztanko, M.; Scott, C. The Influence of Vanadium Additions on Isothermally Formed Bainite Microstructures in Medium Carbon Steels Containing Retained Austenite. Metals 2020, 10, 392. [CrossRef]

19. Zhang, K.; Liu, P.; Li, W.; Guo, Z.-H.; Rong, Y.-H. High Strength-Ductility Nb-microalloyed Low Martensitic Carbon Steel: Novel Process and Mechanism. Acta Met. Sin. Engl. Lett. 2015, 28, 1264-1271. [CrossRef]

20. Yan, S.; Liu, X.; Liang, T.; Chen, J.; Zhao, Y. Effect of Micro-Alloying Elements on Microstructure and Mechanical Properties in C-Mn-Si Quenching and Partitioning (Q\&P) Steels. Steel Res. Int. 2019, 90, 1800257. [CrossRef]

21. Zhang, J.; Ding, H.; Misra, R.; Wang, C. Microstructural evolution and consequent strengthening through niobium-microalloying in a low carbon quenched and partitioned steel. Mater. Sci. Eng. A 2015, 641, 242-248. [CrossRef]

22. Aoued, S.; Danoix, F.; Allain, S.Y.; Gaudez, S.; Geandier, G.; Hell, J.C.; Soler, M.; Gouné, M. Microstructure Evolution and Competitive Reactions during Quenching and Partitioning of a Model Fe-C-Mn-Si Alloy. Metals 2020, 10, 137. [CrossRef]

23. Bhattacharya, D. Role of Niobium in Advanced High Strength Steels for Automotive Applications. J. Iron Steel Res. Int. 2011, 18, 712-717. [CrossRef]

24. Hu, J.; Du, L.-X.; Dong, Y.; Meng, Q.-W.; Misra, R. Effect of Ti variation on microstructure evolution and mechanical properties of low carbon medium Mn heavy plate steel. Mater. Charact. 2019, 152, 21-35. [CrossRef]

25. Thermo-Calc Software TCFE9 Steels/Fe-alloys Database. Available online: https://thermocalc.com/content/uploads/ Documentation/Databases/TCFE_History/tcfe-historytcfe8totcfe9.pdf (accessed on 23 July 2017).

26. Peet, M.; Bhadeshia, H.K.D.H. Materials Algorithms Project. Available online: https://www.phase-trans.msm.cam.ac.uk/map/ steel/programs/mucg83.html (accessed on 2 January 2021).

27. Li, Z.; Wu, D. Effects of Hot Deformation and Subsequent Austempering on the Mechanical Properties of Si-Mn TRIP Steels. ISIJ Int. 2006, 46, 121-128. [CrossRef]

28. Saeglitz, M.; Krauss, G. Deformation, fracture, and mechanical properties of low-temperature-tempered martensite in SAE 43xx steels. Met. Mater. Trans. A 1997, 28,377-387. [CrossRef]

29. Matlock, D.K.; Speer, J.G. Microstructure and Texture in Steels; Haldar, A., Suwas, S., Bhattacharjee, D., Eds.; Springer: Berlin/Heidelberg, Germany, 2009; pp. 185-205.

30. Ebner, S.; Suppan, C.; Stark, A.; Schnitzer, R.; Hofer, C. Austenite decomposition and carbon partitioning during quenching and partitioning heat treatments studied via in-situ X-ray diffraction. Mater. Des. 2019, 178, 107862. [CrossRef]

31. Gladman, T. Precipitation hardening in metals. Mater. Sci. Technol. 1999, 15, 30-36. [CrossRef]

32. He, B.; Pan, S.; Huang, M. Extra work hardening in room-temperature quenching and partitioning medium Mn steel enabled by intercritical annealing. Mater. Sci. Eng. A 2020, 797, 140106. [CrossRef]

33. Dai, J.; Meng, Q.; Zheng, H. An innovative pathway to produce high-performance quenching and partitioning steel through ultra-fast full austenitization annealing. Mater. Today Commun. 2020, 25, 101272. [CrossRef] 